\title{
Catheterisation of a persistent left superior vena cava
}

\author{
Minakshi Boodhun, Nurashikin Mohammad, Azreen Adnan, \\ Wan Syamimee Wan Ghazali
}

Department of Internal Medicine, Universiti Sains Malaysia, Health Campus, Kubang Kerian, Malaysia

\section{Correspondence to}

Dr Wan Syamimee Wan Ghazali, mimeeghazali@yahoo.com

Accepted 16 June 2018
Check for updates

To cite: Boodhun $\mathrm{M}_{\text {, }}$ Mohammad N, Adnan A, et al. BMJ Case Rep Published Online First: [please include Day Month Year]. doi:10.1136/bcr-2018 224355

\section{SUMMARY}

We present a case of a 62-year-old woman with endstage renal disease who displayed a persistent left superior vena cava detected following placement of haemodialysis catheter through the left internal jugular vein (IJV). The diagnosis was confirmed by left internal jugular vein cathetogram, computed tomography (CT) thorax and transthoracic echocardiography. The catheter was removed without immediate complications. She remained well during the outpatient follow-up.

\section{BACKGROUND}

Congenital anomalies of the superior vena cava are incidentally discovered during procedures which include central venous catheter (CVC) insertion, pacemaker electrode placement and cardiopulmonary bypass surgery.

Persistent left superior vena cava (PLSVC) is a rare anomaly found in about $0.3 \%$ of healthy subjects. ${ }^{1}$ This condition results from failure of the left anterior cardinal vein to degenerate during embryological development. Serious complications such as shock, arrhythmias, angina and cardiac arrest have been described during catheterisation of adults with PLSVC. ${ }^{2}$ Catheterisation of this vessel including haemodialysis catheter placement appears to be safe if its drainage into the right atrium is ensured. ${ }^{3}$ The main objective of this case report is to emphasise that any operator who is inserting a haemodialysis catheter in the left jugular or subclavian vein should be aware of the existence of PLSVC.

\section{CASE PRESENTATION}

A 62-year-old woman with end-stage renal disease (ESRD) and underlying ischaemic heart disease presented with a complaint of purulent discharge from her dialysis catheter site for 2 days. On clinical examination, she had a right neck collection from the infection.

She had been on regular haemodialysis via a right internal jugular CVC for over 2 months. She was empirically started on a course of intravenous ceftazidime $1 \mathrm{~g}$ daily and cloxacillin $1 \mathrm{~g}$ every 6 hours. A diagnosis of catheter-related bloodstream infection was made when a positive growth with Corynebacterium striatum was identified from both systemic and desired blood samples. The right internal jugular CVC was removed, and the antibiotic was changed to intravenous vancomycin $1 \mathrm{~g}$ daily. A left internal jugular CVC was inserted to continue the dialysis support. There was no immediate complication postinsertion of the CVC and the arterial blood gases analysis confirmed venous blood. However, it was noted on the chest radiograph (figure 1) that the catheter was on the left side of the cardiac silhouette. There was no evidence of haemopneumothorax. Left internal jugular vein (IJV) cathetogram was performed and showed contrast flow from the left to the right atrium with no opacification of the aorta (video 1).

\section{INVESTIGATIONS}

CT scan of the neck and thorax was done to further evaluate the position of the left IJV CVC (figure 2). A transthoracic echocardiogram (TTE) demonstrated that the tip was not found in either of the ventricles or the atria, and most likely it was behind the left atrial appendage.

\section{DIFFERENTIAL DIAGNOSES}

When a CVC that is supposed to project into the superior vena cava abnormally courses to the left of the mediastinum, the following differential diagnoses should be considered; which could be the inadvertent catheterisation of the:

1. Left internal thoracic vein.

2. Left superior intercostal vein.

3. Left subclavian artery to the descending thoracic aorta.

4. Extravascular position into the mediastinum or pleural space.

\section{MANAGEMENT}

The PLSVC catheter was removed by the cardiothoracic team. There were no complications attributable to the catheter removal. Subsequently, she underwent uneventful placement of a permanent left femoral CVC for continuation of haemodialysis.

\section{OUTCOME AND FOLLOW-UP}

Once the anatomical anomaly was confirmed, the PLSVC catheter was discontinued and the patient had an uneventful hospital course. Her subsequent follow-up did not reveal any complications pertaining to the PLSVC.

\section{DISCUSSION}

PLSVC has an estimated incidence of $0.3 \%-0.5 \% .^{45}$ PLSVC occurs due to the failure of involution of the left cardinal vein during fetal life. It has been known that the presence of PLSVC is related to abnormal electrophysiological functioning of the heart. This is because of the anatomical and structural abnormalities of the conduction tissues and the sinus node (dilation of coronary sinus), ${ }^{6-8}$ resulting in 


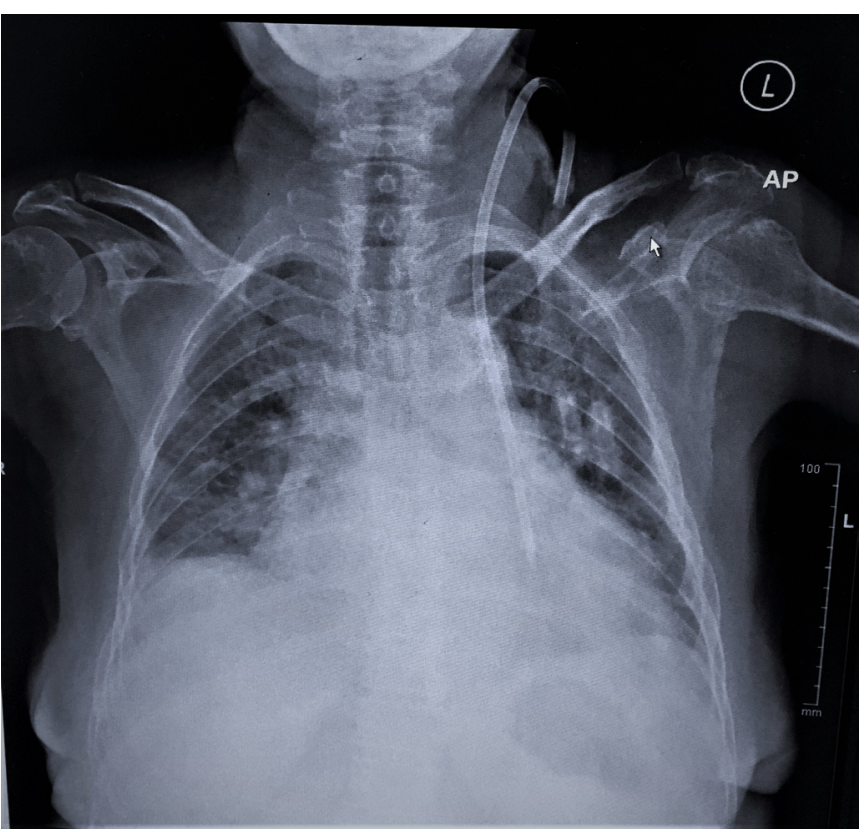

Figure 1 Chest radiograph demonstrating the atypical course of the left central venous catheter. AP, anteroposterior.

bradyarrhythmias (atrioventricular conduction blocks) or tachyarrhythmias (supraventricular tachycardias, atrial fibrillation syndrome).

Most of the dialysis catheters are inserted through the right IJV, and right superior vena cava coexists with PLSVC in more than $80 \%$ of patients, hence rarely reported. ${ }^{9}{ }^{10}$ PLSVC should be considered especially when the CVC via the left subclavian vein or IJV proved to be difficult. It is a known association with other congenital cardiac anomalies such as atrioventricular septal defect, ventricular septal defect and atrial septal defect. ${ }^{11}$ In this case, there was no evidence of cardiac anomalies as shown by the TTE. In general, it is asymptomatic and clinically undetectable. ${ }^{12} 13$ Incidentally, PLSVC is typically detected during catheterising procedures, for example, in haemodialysis catheter placement. It can potentially lead to many serious complications, such as arrhythmias provocation, systemic embolisation, vascular thrombosis, shock, angina and cardiac arrest. ${ }^{2}$

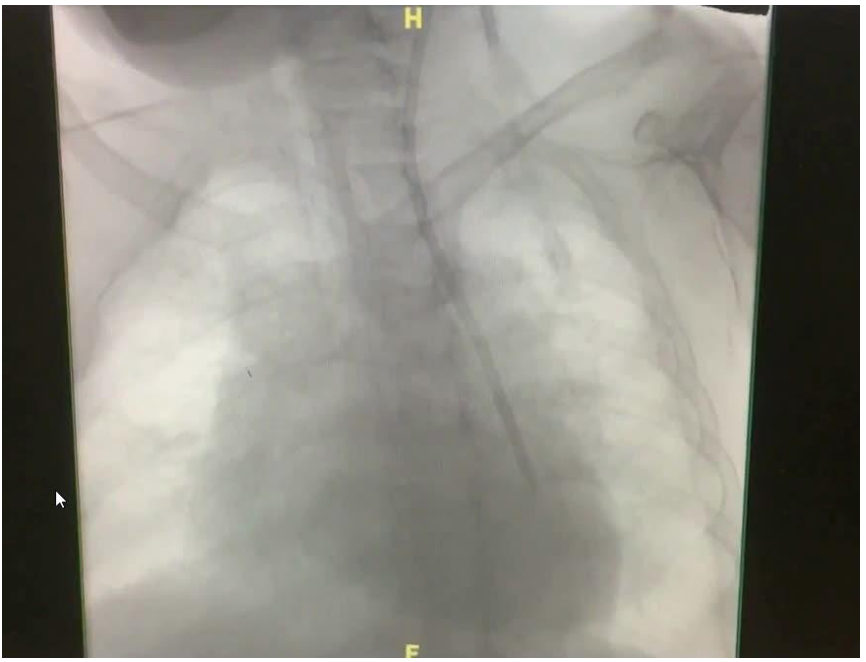

Video 1 Left internal jugular vein cathetogram shows contrast flow from the left to the right atrium with no opacification of the aorta.

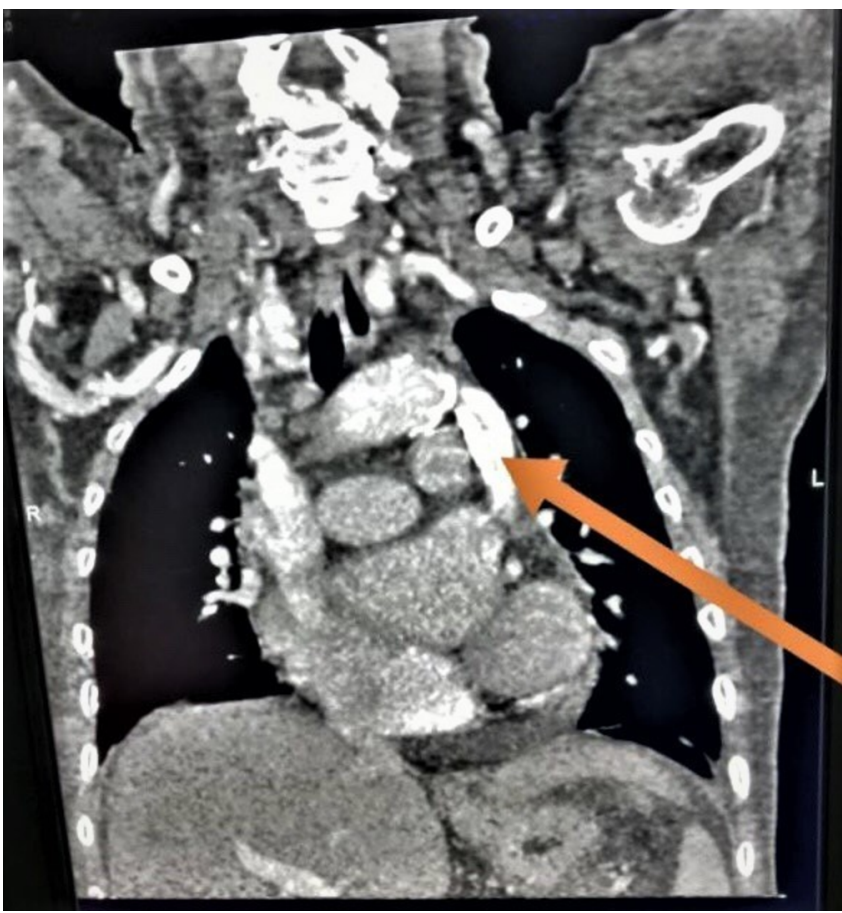

Figure 2 CT scan revealed coronal mediastinal window with contrast showing the left-sided superior vena cava. The arrow showed the tip of the left internal jugular vein in the left superior vena cava.

Left superior vena cava may appear on the posteroanterior chest radiograph where it manifests itself as the widening of the aortic shadow, paramedian stripe, paramediastinal bulging or as a low density line along the upper left margin of the heart. ${ }^{14}$

It can be diagnosed non-invasively by echocardiography in conjunction with Doppler and/or contrast ultrasonography. CT scan and three-dimensional contrast-enhanced magnetic resonance venography are also important diagnostic modalities. ${ }^{6}$

A similar case was reported by Lim et $a l^{11}$ when a catheterising procedure was performed under fluoroscopy. Initially they thought it was an arterial puncture. After confirming a venous puncture, they proceeded with the insertion of the catheter. A digital subtraction angiography revealed the PLSVC, and the patient was haemodialysed using the catheter for 5 months without any complications. ${ }^{7}$ Jang et al described another case when they had to insert a left-sided temporary dual lumen catheter on a patient with fistula failure, and the chest radiograph showed that the catheter tip was on the left paramediastinal side (similar to our case). ${ }^{8}$ The catheter was not removed immediately. After confirming the location of the catheter by CT scan, the diagnosis of PLSVC was made. Another case of PLSVC was reported by Stylianou et al, ${ }^{15}$ which was diagnosed incidentally after replacement of the haemodialysis catheter via the left IJV. Abnormal position of the catheter tip in the left paramediastinal area was revealed by the chest radiograph. CT scan and TTE were done to establish the diagnosis. She had been using the catheter for dialysis for a month before she was able to proceed with the newly fashioned graft.

With the rise in the number of patients with ESRD on haemodialysis in Malaysia, it is essential for clinicians who insert CVC to be aware of this congenital anomaly to prevent further complications. Moreover, it is vital to exclude other concomitant cardiac anomalies such as septal defects to prevent systemic embolism following thrombosis of the CVC. 


\section{Learning points}

- Patent left superior vena cava (persistent left superior vena cava (PLSVC)) has been diagnosed in $0.3 \%-0.5 \%$ of the general population.

- It results from the persistence of the left cardinal vein that usually involutes in later life.

- Serious complications such as shock, angina, cardiac tamponade and cardiac arrest have been described during catheterisation in adults with PLSVC.

- When difficulty arises on central venous catheterisation via the internal jugular or subclavian vein, variations of the superior vena cava should be entertained.

- It is paramount to ascertain the drainage pattern of PLSVC with venogram, echocardiography and CT prior to long-term catheterisation.

Acknowledgements We would like to express our gratitude to Dr Abu Dzar Ganesh Abdullah, who assisted us in producing the images and helped us in editing the manuscript.

Contributors MB prepared and drafted the manuscript. AA managed the patient. WSWG and NM edited and approved the final draft of the manuscript.

Funding The authors have not declared a specific grant for this research from any funding agency in the public, commercial or not-for-profit sectors.

Competing interests None declared.

Patient consent Obtained.

Provenance and peer review Not commissioned; externally peer reviewed.

(c) BMJ Publishing Group Ltd (unless otherwise stated in the text of the article) 2018. All rights reserved. No commercial use is permitted unless otherwise expressly granted.

\section{REFERENCES}

1 Rossi UG, Rigamonti P, Torcia P, et al. Congenital anomalies of superior vena cava and their implications in central venous catheterization. J Vasc Access 2015;16:265-8.

2 Granata A, Andrulli S, Fiorini F, et al. Persistent left superior vena cava: what the interventional nephrologist needs to know. J Vasc Access 2009;10:207-11.

3 Parreira LF, Lucas CC, Gil CC, et al. Catheterization of a persistent left superior vena cava. J Vasc Access 2009; 10:214-5.

4 Schummer W, Schummer C, Fröber R. Persistent left superior vena cava and central venous catheter position: clinical impact illustrated by four cases. Surg Radiol Anat 2003:25:315-21.

5 Deshpande R, Band M, Kurup V. Persistent left superior vena cava: unusual catheter position on chest X-ray Film. Anesthesiology 2017;127:165.

6 Uçar $\mathrm{O}$, Paşaoğlu L, Ciçekçioğlu H, et al. Persistent left superior vena cava with absent right superior vena cava: a case report and review of the literature. Cardiovasc J Afr 2010;21:164-6.

7 Sheikh AS, Mazhar S. Persistent left superior vena cava with absent right superior vena cava: review of the literature and clinical implications. Echocardiography 2014;31:674-9.

8 Duymus M, Yesilkaya Y, Orman G, et al. Persistent left superior vena cava draining to the left atrium: A case report and review of the literature. Pol I Radiol 2012;77:65-6

9 Kuppusamy TS, Balogun RA. Unusual placement of a dialysis catheter: persistent left superior vena cava. Am J Kidney Dis 2004;43:365-7.

$10 \mathrm{Kim}$ YO, Choi EJ, Jeon HK, et al. Persistent left superior vena cava detected by hemodialysis catheterization. Nephron 1999;83:87-88.

11 Lim TC, H'ng MW. Persistent left superior vena cava: a possible site for haemodialysis catheter placement. Singapore Med J 2010;51:e195-7.

12 Jang YS, Kim SH, Lee DH, et al. Hemodialysis catheter placement via a persistent left superior vena cava. Clin Nephrol 2009;71:448-50.

13 Higgs AG, Paris S, Potter F. Discovery of left-sided superior vena cava during central venous catheterization. Br J Anaesth 1998;81:260-1.

14 Cha EM, Khoury GH. Persistent left superior vena cava. Radiologic and clinical significance. Radiology 1972;103:375-81.

15 Stylianou K, Korsavas K, Voloudaki A, et al. Can a left internal jugular catheter be used in the hemodialysis of a patient with persistent left superior vena cava? Hemodial Int 2007:11:42-5.

Copyright 2018 BMJ Publishing Group. All rights reserved. For permission to reuse any of this content visit http://group.bmj.com/group/rights-licensing/permissions.

BMJ Case Report Fellows may re-use this article for personal use and teaching without any further permission.

Become a Fellow of BMJ Case Reports today and you can:

- Submit as many cases as you like

- Enjoy fast sympathetic peer review and rapid publication of accepted articles

- Access all the published articles

- Re-use any of the published material for personal use and teaching without further permission

For information on Institutional Fellowships contact consortiasales@bmjgroup.com

Visit casereports.bmj.com for more articles like this and to become a Fellow 